\title{
A agenda do trabalho decente no contexto do Mercosul
}

\author{
Lenir Aparecida Mainardes da Silva \\ Silvana Souza Neto Mandalozzo
}

\section{SciELO Books / SciELO Livros / SciELO Libros}

SILVA, L. A. M., and MANDALOZZO, S. S. N. A agenda do trabalho decente no contexto do Mercosul. In: COSTA, L. C., NOGUEIRA, V. M. R., and SILVA, V. R., orgs. A política social na América do Sul: perspectivas e desafios no século XXI [online]. Ponta Grossa: Editora UEPG, 2013, pp. 113-129. ISBN 978-85-7798-231-8. Available from: doi: 10.7476/9788577982318.0006. Also available in ePUB from: http://books.scielo.org/id/rfv9p/epub/costa-9788577982318.epub.

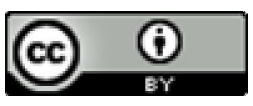

All the contents of this work, except where otherwise noted, is licensed under a Creative Commons Attribution $\underline{4.0 \text { International license. }}$

Todo o conteúdo deste trabalho, exceto quando houver ressalva, é publicado sob a licença Creative Commons Atribição 4.0.

Todo el contenido de esta obra, excepto donde se indique lo contrario, está bajo licencia de la licencia Creative Commons Reconocimento 4.0. 


\section{A agenda do trabalho decente no contexto do}

Mercosul

Lenir Aparecida Mainardes da Silva; Silvana Souza Neto Mandalozzo

\section{Introdução}

O presente texto aborda questões do trabalho decente no Mercado Comum do Cone Sul (Mercosul), de forma interdisciplinar, enfocando o viés social e também jurídico. Para tanto, houve a divisão em quatro partes, a saber: a. A discussão do trabalho no processo de integração regional do Mercosul; b. A Agenda do Trabalho Decente conforme a OIT; c. A incorporação da Agenda do Trabalho Decente nos países do Mercosul e d. O trabalho decente no Brasil.

A categoria "trabalho" se desenvolve mundialmente e, portanto, também nos países integrantes da organização ora analisada. Para o desenvolvimento deste trabalho deve ser integrada a questão da decência, importante em qualquer situação, tanto que apregoada pela Organização Internacional do Trabalho (OIT).

A OIT preocupa-se com a questão de forma pormenorizada desde 1998, quando aprovou a Declaração sobre os princípios e direitos fundamentais no trabalho e seu seguimento.

O Brasil, seguindo esta tendência mundial, adotou a preocupação e vem atuando de forma positiva para a existência de trabalho decente, com medidas práticas, as quais serão analisadas. Tem-se que um dos grandes avanços ocorridos foi a participação da sociedade civil organizada nas questões sociais da organização, com medidas concretas.

Logo, o estudo apresenta um viés de modernidade, com a adequação do trabalho à decência, não se podendo deixar de lado o resgate de alguns acontecimentos históricos que levaram a esta preocupação.

A pretensão não é o esgotamento do assunto, mas traçar os elementos fundamentais que levam à compreensão do "trabalho decente" a ser desenvolvido no Mercosul.

\section{A discussão do trabalho no processo de integração regional do Mercosul}

O homem sempre esteve envolvido com o trabalho, afinal, é dele que retira os meios para sobrevivência. Esse trabalho foi ganhando novos contornos, chegando-se à época da Revolução Industrial, quando houve a 
preponderância factual em que o homem coloca à disposição a sua mão de obra, e com isso aufere a contraprestação respectiva.

$\mathrm{Na}$ atualidade, o trabalho é um elemento de suma importância no mundo capitalista, é essencial à produção e hoje encontra campo profícuo na prestação de serviços.

O trabalho humano se desenvolve em todos os países integrantes do Mercosul. Estes países, relembrando, são Argentina, Brasil, Paraguai e Uruguai, além do Chile e Bolívia, sendo que estes dois últimos ressalvaram que não participariam da união aduaneira (SÜSSEKIND, 2000, p.436). A Colômbia, o Equador e a República do Peru entraram também na organização com a mesma condição de Estados associados, tal como o Chile e Bolívia (BARROS, 2011, p.53). A Venezuela incorporada recentemente ao Mercosul.

A constitucionalização do Direito do Trabalho e da Seguridade Social "é uma das pedras angulares da ordem constitucional dos países do Mercosul". Estes ramos do direito encontram-se inseridos dentro dos direitos sociais. Estes "são direitos de proteção que para serem eficazes necessitam de maior grau de regulamentação, especificação ou precisão e atividade do Estado" (BARROS, 2011, p.130 e 131).

Os quatro países membros fundadores do Mercosul possuem normas de proteção ao trabalho inseridas constitucionalmente, o que demonstra a proteção especial a esse tipo de atividade.

Mas essa proteção constitucional ao trabalho, por si só, não assegura nenhuma igualdade ou harmonização, como exposto a seguir:

Os modelos de Constituição dos países-membros são, por assim dizer, fechados, não prevendo o advento do direito supranacional, elaborado por fontes que deles receberam competência normativa. O direito comunitário, resultado do exercício dessa competência normativa, não lhes é hierarquicamente superior. Nasce, porém, para conviver no mesmo nível, razão pela qual há de se passar pela adaptação da Constituição Federal. (BARROS, 2011, p.174).

A questão sobre o trabalho não foi deixada de lado por este organismo internacional. Foi criado o Subgrupo de Trabalho n ${ }^{\circ} 11$, denominado de Assuntos Laborais, através da Resolução MERCOSUL/GMC no 11/91. Posteriormente, houve a alteração da nomenclatura para Relações Laborais, Emprego e Seguridade Social, através da Resolução MERCOSUL/GMC n 11/91. Este Subgrupo foi subdividido em oito comissões de trabalho - Relações Individuais de Trabalho, Relações Coletivas de Trabalho, Emprego, Formação Profissional, Saúde e Segurança do Trabalho, Seguridade Social, Setores Específicos e Princípios (SÜSSEKIND, 2000, p.437 e 438). 
Neste tópico, interessante foi a proposta do então Ministro do Trabalho do Brasil, em 10 de dezembro de 1991, para que este subgrupo tivesse a composição tripartite, ou seja, composta de representantes governamentais, de trabalhadores e empregadores (BARROS, 2011, p.51). Essa composição, quando envolve aspectos trabalhistas, mostra-se oportuna, pois colhe a opinião dos atores sociais envolvidos na temática.

O subgrupo de trabalho foi renumerado, passando a ser identificado pelo $\mathrm{n}^{\circ} 10$, estando a finalidade bem delineada, como se verifica:

\section{SubGrupo de Trabalho n ${ }^{\circ} 10$ - SGT 10}

O SGT 10 é de integração tripartite e debate aspectos relativos às políticas de emprego, legislações trabalhistas e aplicação das convenções da OIT no Mercosul. Faz levantamentos, através do Observatório do Mercado de Trabalho, a evolução do mercado de trabalho no Mercosul. Faz pesquisas sobre a situação dos trabalhadores migrantes e fronteiriços no Mercosul. Promove ações sobre qualificação e formação profissional, bem como sobre saúde, segurança no trabalho, inspeção do trabalho e seguridade social. ${ }^{1}$

Cada país possui as suas características, regulamentando a categoria do trabalho. O ideal seria que todos os países membros possuíssem a mesma regulamentação trabalhista e previdenciária, o que permitiria a efetiva livre circulação de trabalhadores.

Os países membros do Mercosul possuem uma estrutura jurídica que, aliando-se à soberania interna, encontra dificuldade para a harmonização da legislação trabalhista. Tais empecilhos são bem encontrados na doutrina:

Harmonização do Direito social-trabalhista - As dificuldades para harmonizar os sistemas jurídicos no campo social-trabalhista, seja no que tange às relações individuais e coletivas do trabalho, seja no âmbito da solução dos litígios trabalhistas ou, ainda, no concernente à previdência social, decorrem tanto da diversidade dos correspondentes sistemas jurídicos, quando da ainda inadmissível tese da adoção de diretrizes e normas regulamentares por órgãos interestatais regionais com a conseqüente limitação do poder de legislar dos Estados-membros da entidade. (SÜSSEKIND, 2000, p.439).

A importância da harmonização da legislação trabalhista que envolve o contrato de trabalho é um dos assuntos abordados por especialistas, como se verifica:

\footnotetext{
Comissão Sociolaboral e SGT-10. Disponível em: < http://www.mte.gov.br/rel_internacionais/ comissao_sociolaboral.asp>. Acesso em: 02 set. 2011.
} 
A visão do Direito do Trabalho favorece a integração ou tem grande contribuição para dar, porque o contrato de trabalho não é observado como um contrato comum, com duas partes contratantes, pessoas físicas e jurídicas, mas é normal o juslaboralista ter em mente a composição político-econômica que está por trás daquele simples contrato laboral, e isso ocorre dentro de cada Estado, concluindo-se que ocorrerá também dentro da região a ser integrada. (HUSEK, 1998, p.143).

Uma das primeiras soluções para a harmonização das legislações trabalhistas dos quatro países membros fundadores do Mercosul foi a estratégia de ratificação das mesmas Convenções da OIT, como se verifica:

No caso da estratégia mais estritamente trabalhista, ela privilegiou a ratificação pelos quatro países do bloco regional de um pacote de convenções mais importantes da OIT e a elaboração de uma Carta Social ou de Direitos Fundamentais do Mercosul, visando a estabelecer um "mínimo inderrogável a partir do qual se promova a equiparação na base das melhores condições e direitos sociais existentes. (VIGEVANI, 1998, p.118).

No Mercosul, houve a intenção de ratificação de trinta e quatro convenções da OIT, previamente selecionadas. Mas isso não foi possível, pois somente onze delas tinham sido ratificadas pelos quatro países fundadores da organização (SÜSSEKIND, 2000, p.41).

Atualmente, são as seguintes convenções ratificadas pelos quatro países membros originários da organização:

- Convenção n. 11 - Sobre o Direito de Associação (Agricultura) - 1921;

- Convenção n. 14 - Sobre o Descanso Semanal (Indústria) - 1921;

- Convenção n. 26 - Sobre os métodos para Fixação do Salário Mínimo 1928;

- Convenção n. 29 - Trabalho forçado - 1930;

- Convenção n. 81 - Sobre a Inspeção do Trabalho - 1947;

- Convenção n. 95 - Sobre a Proteção do Salário - 1949

- Convenção n. 98 - Sobre o Direito de Sindicalização e de Negociação Coletiva - 1949;

- Convenção n. 100 - Sobre a Igualdade de Remuneração - 1951;

- Convenção n. 105 - Sobre a Abolição do Trabalho Forçado - 1957;

- Convenção n. 111 - Sobre a Discriminação (Emprego e Ocupação) 1958;

- Convenção n. 115 - Proteção contra radiação - 1960;

- Convenção n. 138 - Idade mínima -1973;

- Convenção n. 159 - Sobre a Readaptação Profissional e o Emprego (Pessoas Inválidas) - 1983;

- Convenção n. 182 - Piores formas de trabalho infantil - 1999. (BARROS, 2011, p.71 e 72) 
A ratificação das mesmas Convenções da OIT não é processo simples, pois cada país se submete a normas internas de seu ordenamento jurídico. Enfim, é um processo que demanda tempo e análise complexa pelos órgãos competentes. No Brasil, o ato de ratificação é complexo ante os termos dos artigos 49, I e 84, VIII, da Constituição da República.

Os movimentos sindicais também tiveram um papel decisivo nas questões trabalhistas do Mercosul. Até 1992, permaneceram em atitude defensiva. Mas a partir do ano citado e do posterior, especialmente com a Central Única dos Trabalhadores (CUT) do Brasil, houve um esforço para a participação nas questões de integração regional. As centrais dos quatro países fundadores passam a participar de Subgrupos e empreendem atividade de "discussão com os órgãos públicos participantes do processo negociador e com diversas entidades empresariais" (VIGEVANI, 1998, p.77).

Cita-se que no ordenamento jurídico brasileiro, as centrais sindicais passaram a integrar o sistema confederativo e com isso ganharam força e existência jurídica plenamente reconhecida, como se verifica pelo artigo 590, II, "b", da CLT, com a introdução efetuada pela Lei 11.648 de 30 de março de 2008. Com esta inclusão, as centrais sindicais passaram a ter direito à parcela da contribuição sindical obrigatória paga pelos empregados anualmente.

As outras entidades sindicais, como confederações, federações e sindicatos até poderiam se internacionalizar, e assim ganhar força para a negociação de direitos junto aos países membros. Ocorre que, com os fenômenos de flexibilização dos direitos trabalhistas, terceirização e globalização dentre outros, estes movimentos encontram-se enfraquecidos e perdem o poder de atuação em nível maior, mantendo a sua influência via de regra, nas bases municipais ou estaduais.

Em 1986, houve a criação da Coordenadoria das Centrais Sindicais do Cone Sul (CCSCS), extraindo-se o seguinte quanto a sua fundação:

Participaram da sua fundação a COB boliviana, o Movimento Intersindical de Trabalhadores (MIT) paraguaio (que mais tarde mudou de nome para CUT), o Comando Nacional dos Trabalhadores (CNT) e a Central Democrática de Trabajadores (CDT) chilenos (que posteriormente se fundiram na CUT), A CGT argentina, o PIT-CNT uruguaio e a CUT e CGT brasileiras. (VIGEVANI, 1998, p.109).

Essa Coordenadoria atua ativamente no Mercosul. Cronologicamente, em dezembro de 1991, sugeriu a criação de um subgrupo de emprego e relações de trabalho, originando esta divisão até hoje vigente. Em dezembro de 1992, alertou para impactos econômicos e sociais, denunciando a falta de importância para a negociação de questões trabalhistas, reivindicando a adoção de uma Carta dos Direitos Fundamentais para o Mercosul. Em dezembro de 1994, 
elaborou documento com propostas sobre o trabalho, social, econômica, produtiva e estrutura institucional da organização, defendendo a criação de um fórum de representação da sociedade civil. Em junho de 1996, foi criado o Fórum Consultivo Econômico Social do Mercosul (FCES), com a participação ativa da Coordenadoria, sendo que este fórum detém direito de iniciativa ao Grupo de Mercado Comum (GMC). ${ }^{2}$

Denota-se que a preocupação com o aspecto social no Mercosul sempre existiu e, para tanto, um dos aspectos mais importantes é a questão de um patamar mínimo de direitos enquadráveis na área do trabalho humano.

Em 1997, a CCSCS apresentou a proposição de criar um observatório do corpo técnico de gestão do mercado tripartite. Para os anos de 2002 e 2003, a Coordenadoria passa a atuar em dois níveis, um deles com coordenação setorial, monitorando políticas públicas e empresas multinacionais, a fim de alcançar efeitos supranacionais de acordos coletivos. O outro nível com coordenação intersetorial, criando Comitê de Desenvolvimento Produtivo, formado pelos setores de agronegócio, indústria e infraestrutura, com a intenção de desenvolver produtos para a região.

Segundo se extrai do último site citado da CCSCS, as seguintes entidades estão relacionadas como sindicatos centrais: CGT Argentina, CTA Argentina, UGT Brasil, CUT Brasil, Força Sindical Brasil, CAT Chile, CUT Chile, CNT Paraguai, Paraguai CUT, CUT para o Paraguai, PIT-CNT do Uruguai, CGTB - Brasil e CTB - Brasil.

Um avanço na área social foi a Declaração Sociolaboral do Mercosul, assinada em 10 de dezembro de 1998. Os Estados membros afirmam por esta Declaração que estão comprometidos com as declarações, pactos, protocolos e outros tratados que integram o patrimônio jurídico da humanidade. Mesmo não possuindo a forma de um protocolo, por se tratar de ato solene, aceito pelos presidentes dos Estados, geram efeitos importantes:

(i) inspira interpretações, normas e políticas públicas e permite fundamentar demandas e sentenças; (ii) em alguns países poderá ser elevada à categoria de princípio constitucional, por dizer respeito a direitos fundamentais da pessoa humana; (iii) comprometeria os governos signatários a pelo menos não atuarem contra o que proclamaram; e (iv) contribui para hierarquizar o trabalho no marco de processos de integração regional marcadamente economicistas, como foi o do Mercosul. (URIARTE, 1997, p.63 apud BARROS, 2011, p.57).

2 COORDINADORA DE CENTRALES SINDICALES DEL CONO SUR. Disponível em: <http://www.ccscs.org/>. Acesso em: 04 set. 2011. 
Esta Declaração foi pactuada pelos quatro Estados partes que instituíram o Mercosul ${ }^{3}$. Embora nada trata de forma específica sobre o trabalho decente, abordou diversos temas interligados a este, como não discriminação, promoção de igualdade, trabalhadores migrantes e fronteiriços, eliminação do trabalho forçado, trabalho infantil e de menores, direitos dos empregadores, liberdade de associação, liberdade sindical, negociação coletiva, greve, diálogo social, fomento social, proteção dos desempregados, formação profissional e desenvolvimento de recursos humanos, saúde e segurança no trabalho, inspeção do trabalho e seguridade social.

O artigo 21 da Declaração dispôs sobre reunião anual para avaliar as questões nos seguintes termos: "A Comissão Sociolaboral Regional deverá reunir-se ao menos uma vez ao ano para analisar as memórias oferecidas pelos Estados partes e preparar relatório a ser elevado ao Grupo Mercado Comum”. Isso demonstra a intenção dos Estados quanto à melhoria das condições sociais e de trabalho. Sobre esta Comissão, as atribuições encontram-se bem definidas:

\section{Comissão Sócio-Laboral - CSL}

Órgão tripartite, integrado por representantes governamentais, dos trabalhadores e das empresas. Apóia os trabalhos do GMC, com caráter promocional e não sancionador, cujo objetivo de fomentar e acompanhar a aplicação da Declaração Sociolaboral do Mercosul. ${ }^{4}$

Esta Comissão teve sua $19^{a}$ reunião na cidade de Buenos Aires, em 2006, com a presença da delegação dos países do Brasil, Argentina, Uruguai e Venezuela, segundo o site consultado 5 . Pelo que se depreende da Ata analisada (assinada em 23 de junho de 2006), constante no site citado, três questões foram analisadas, a da própria Comissão, memória da liberdade sindical e de associação, memória de diálogo social e Resolução 59/2001, do Grupo Mercado Comum (GMC).

Esta Comissão tem o apoio da OIT, que colabora inclusive fornecendo suporte para que o Estado membro elabore as memórias sobre determinado assunto.

3 DECLARAÇÃO SOCIOLABORAL DO MERCOSUl. Disponível em: <http://www.stf. jus.br/arquivo/cms/forumCorteSupremaNorma/forumCorteSupremaNorma_AP_75320.pdf.>. Acesso em: 02 set. 2011.

4 Comissão Sociolaboral. Disponível em: <http://www.mte.gov.br/rel_internacionais/comissao_ sociolaboral.asp>. Acesso em: 02 set. 2011.

5 MERCOSUR/GMC/CSL/Acta 1/06 - XIX REUNIÓN DE LA COMISIÓN SOCIOLABORAL DEL MERCOSUR. Disponível em: <http://www3.mte.gov.br/rel_ internacionais/ActaCSLFINAL23_06_2006.pdf>. Acesso em: 24 jun. 2012. 
A colaboração da OIT, organizada mundialmente com um organismo regionalizado, demonstra a importância do amadurecimento de questões sócio-trabalhistas para que sejam tratadas de forma similar.

A sociedade civil organizada também tem a sua participação no Mercosul. Em 2004, foi fundado o Observatório de Políticas Públicas de Direitos Humanos no Mercosul, que tem como objetivo "incidir nas políticas públicas de direitos humanos nos países do bloco. Para cumprir com esse propósito, capacita e promove a participação da sociedade civil nos âmbitos institucionais do Mercosul". ${ }^{6}$

Atualmente, este observatório referenciado no parágrafo imediatamente anterior é composto de doze organizações: Centro de Estudos Legais e Sociais (CELS), o Serviço Argentino de Direitos Humanos (SADH) e o Centro de Direitos Humanos e Ambiente (CEDHA), da Argentina; o Instituto Sou da Paz, Themis-Assessoria Jurídica e Estudos de Gênero e Conectas Direitos Humanos, do Brasil; o Instituto Paraguaio de Direitos Humanos (IPDH), Comissão de Igrejas para Ajuda de Emergência (CIPAE) e Raízes para o Fortalecimento e o Desenvolvimento, do Paraguai; o Serviço Paz e Justiça (SERPAJ), o Instituto Solidariedade e Desenvolvimento (ISODE) e o Instituto de Estudos Legais e Sociais do Uruguai (IELSUR), pelo Uruguai.

O observatório tem participação com medidas práticas, acompanhando o caminho da agenda do Mercosul, participando de reuniões, realizando seminários e eventos de direitos humanos e capacitação.

O Decreto 6.594, de 06 de outubro de 2008, instituiu no âmbito do Poder Executivo brasileiro (Secretaria-Geral da Presidência da República e Ministério das Relações Exteriores), o Programa Mercosul Social e Participativo, com o objetivo de promover a interlocução entre o Governo Federal e as organizações da sociedade civil sobre as políticas públicas. As finalidades estão definidas no artigo $2^{\circ}$ :

Art. 2ㅇ O Programa Mercosul Social e Participativo tem as seguintes finalidades:

I - divulgar as políticas, prioridades, propostas em negociação e outras iniciativas do Governo brasileiro relacionadas ao MERCOSUL;

II - fomentar discussões no campo político, social, cultural, econômico, financeiro e comercial que envolvam aspectos relacionados ao MERCOSUL; III - encaminhar propostas e sugestões que lograrem consenso, no âmbito das discussões realizadas com as organizações da sociedade civil, ao Conselho do Mercado Comum e ao Grupo do Mercado Comum do MERCOSUL.

6 OBSERVATÓRIO. Disponível em: <http://www.observatoriomercosur.org.uy/pr/observatorio.php>. Acesso em: 24 jun. 2012. 
Participam deste Programa os órgãos e entidades da administração pública federal e as organizações da sociedade civil convidadas. Esta participação demonstra um entrelaçamento efetivo entre o setor público e a sociedade civil. Para a efetivação, podem ser requisitados servidores dos órgãos e entidades da administração pública federal e ainda há a previsão de orçamento na forma definida no Decreto. Nas reuniões do conselho, participam vários segmentos da sociedade, englobando representantes dos trabalhadores e empregadores, atores sociais integrantes do mundo do trabalho, como se verifica:

Participam das reuniões do Conselho representantes de centrais sindicais, confederações da agricultura familiar, pastorais sociais, movimento negro, cooperativas, organizações de pequenos e médios empresários e de entidades que tratam de economia solidária, direitos humanos, mulheres, juventude, meio ambiente, saúde, educação, cultura, e direitos das pessoas com deficiência, entre outros.

Em 17 de dezembro de 2010, foi assinada a Declaração Especial dos Presidentes dos Estados Partes do Mercosul e Estados Associados sobre Migrações. Tal documento reveste-se de importância no campo laboral, pois permite o tratamento igualitário do trabalhador que presta serviço em outro país da organização. A preocupação com o assunto é demonstrada a seguir:

Nesse sentido, ratificaram a necessidade de garantir o respeito e a promoção dos Direitos Humanos dos migrantes e de suas famílias, independentemente de sua nacionalidade, condição migratória, origem étnica, gênero, idade ou qualquer outra consideração discriminatória. Finalmente, reiteraram a importância de avançar gradualmente em direção à conformação de um espaço regional de livre circulação de pessoas seguro, respeitando a legislação interna do Estado receptor e em concordância com o pleno exercício dos direitos dos migrantes, como um dos pilares fundamentais do processo de integração. Isso contribuirá ativamente para a integração plena dos migrantes nos países de destino, a igualdade nas condições de acesso à educação, saúde e trabalho, bem como o desenvolvimento integral dos países de origem dos fluxos migratórios. ${ }^{8}$

Alguns apregoam que a existência de um tribunal supranacional asseguraria o cumprimento dos preceitos trabalhistas de forma igualitária nos Estados membros do Mercosul. A princípio, não há previsão de um tribunal

\footnotetext{
MERCOSUL SOCIAL E PARTICIPATIVO. Disponível em: < http://www.mercosul.gov.br/ mercosul-social-e-participativo >. Acesso em: 05 set. 2011.

8 Declaração Especial dos Presidentes dos Estados Partes do Mercosul e Estados Associados sobre Migrações. Disponível em: <http://www.mercosul.gov.br/comunicados/2010/declaracao-especial-dos-presidentes-dos-estados-partes-do-mercosul-e-estados-associados-sobre-migracoes $>$. Acesso em: 05 set. 2011.
} 
nestes moldes, e mesmo que houvesse, isso não asseguraria o pleno cumprimento igualitário das normas trabalhistas. Sobre o assunto, estudiosos já se manifestaram, como se verifica:

A maioria dos estudiosos de prestígio tem sugerido para o Mercosul um sistema semelhante ao europeu, que lhe permitiria, com os atributos de uma organização comunitária, na esfera internacional, não depender dos órgãos judiciais internos dos Estados-Partes, bem como a criação de sua própria jurisprudência. A criação de um órgão, nos moldes do Tribunal de Justiça europeu, é a proposta apresentada pelos doutrinadores. (MAGALHÃES, 2000, p. 60).

Como analisado, avanços na área social estão ocorrendo. No campo específico do trabalho, "apesar do tempo decorrido, ainda não permite prognósticos seguros, de certo modo, os prognósticos se mostram imprudentes sob o ponto de vista científico" (BARROS, 2011, p.169).

\section{A Agenda do Trabalho Decente conforme a OIT}

A Constituição da OIT contém em seu preâmbulo dispositivos que expressam a finalidade da Organização criada em 1919:

Considerando que a paz para ser universal e duradoura deve assentar sobre a justiça social;

Considerando que existem condições de trabalho que implicam, para grande número de indivíduos, miséria e privações, e que o descontentamento que daí decorre põe em perigo a paz e a harmonia universais, e considerando que é urgente melhorar essas condições no que se refere, por exemplo, à regulamentação das horas de trabalho, à fixação de uma duração máxima do dia e da semana de trabalho, ao recrutamento da mão-de-obra, à luta contra o desemprego, à garantia de um salário que assegure condições de existência convenientes, à proteção dos trabalhadores contra as moléstias graves ou profissionais e os acidentes do trabalho, à proteção das crianças, dos adolescentes e das mulheres, às pensões de velhice e de invalidez, à defesa dos interesses dos trabalhadores empregados no estrangeiro, à afirmação do princípio "para igual trabalho, mesmo salário", à afirmação do princípio de liberdade sindical, à organização do ensino profissional e técnico, e outras medidas análogas;

Considerando que a não adoção por qualquer nação de um regime de trabalho realmente humano cria obstáculos aos esforços das outras nações desejosas de melhorar a sorte dos trabalhadores nos seus próprios territórios. ${ }^{9}$

9 CONSTITUIÇÃO DA ORGANIZAÇÃO INTERNACIONAL DO TRABALHO (OIT) E SEUS ANEXOS. Disponível em: < http://www.oit.org.br/sites/default/files/topic/decent_work/ doc/constituicao_oit_538.pdf>. Acesso em: 02 set. 2011. 
Vislumbra-se neste preâmbulo a preocupação com o mundo do trabalho, a pessoa trabalhadora é possuidora de direitos básicos para sobrevivência não só em época produtiva, mas também para época posterior.

A OIT, com os propósitos mencionados, é detentora de ampla estrutura para dar suporte às suas finalidades. A função normativa, com as Convenções e Recomendações, abrangem uma gama muito ampla de assuntos. Não bastaria a aprovação e ratificação das Convenções para que as normas tivessem efetividade.

O Brasil é um dos membros fundadores da OIT, dentre os vinte e nove, signatários do Tratado de Versalhes, assinado em 1919, sendo que esta qualidade decorria automaticamente da integração à Sociedade das Nações (SÜSSEKIND, 2000, p.130).

Em 1926, foi criada a Comissão de Peritos para a Aplicação de Convenções e Recomendações, como se denota:

Criado em 1926 pelo Conselho de Administração em virtude de resolução da Conferência Internacional do Trabalho, a Comissão de Peritos é composta de vinte juristas independentes de altíssimo nível, tais como juízes ou ex-juízes da Corte Internacional de Justiça, juízes de Tribunal Superior ou professores eminentes. Esses peritos são escolhidos por sua capacidade técnica e total independência e imparcialidade. São designados pelo Conselho de Administração sob recomendação do Diretor Geral. O seu mandato é renovável a cada três anos. Além disso, para garantir que a Comissão de Peritos seja tão abrangente quanto as normas cuja implementação tem de monitorar, não se poupam esforços para assegurar-se de que represente os vários sistemas jurídicos, sociais e culturais existentes no mundo. (BEAUDONNET, 2011, p.69).

Esta Comissão avalia a aplicação efetiva das Convenções nos países membros. A verificação com estudos independentes traz a segurança necessária para que os objetivos da OIT sejam atingidos.

A Comissão de Peritos examina relatórios dos governos e observações enviadas pelos parceiros sociais quanto às Convenções ratificadas e apresenta os comentários, que podem ser "observações" ou "solicitações diretas" (BEAUDONNET, 2011, p.70)..$^{10}$

De forma específica, não existe uma Convenção da OIT que aborde a questão do trabalho decente, mas várias Convenções em conjunto possuem

\footnotetext{
10 Um brasileiro atualmente compõe esta Comissão de Peritos, Lelio Bentes Correa, Ministro do Tribunal Superior do Trabalho, ex-procurador do Trabalho, professor da Unidade de Trabalho e coordenador do Centro de Direitos Humanos do Instituto de Ensino Superior de Brasília. In: FÓRUM INTERNACIONAL SOBRE DIREITOS SOCIAIS. Disponível em: < http://www.tst. gov.br/ASCS/forum/comissao.html>. Acesso em: 02 set. 2011.
} 
essa preocupação e uma vez existindo a ratificação, a aplicabilidade será analisada através dos relatórios enviados à Comissão de Peritos.

Cumpre fornecer a noção básica do que constitui a expressão trabalho decente. Ela é bem delineada pela OIT, sendo esta uma das preocupações basilares da organização. Verifica-se o alcance:

O Trabalho Decente é o ponto de convergência dos quatro objetivos estratégicos da OIT: o respeito aos direitos no trabalho (em especial aqueles definidos como fundamentais pela Declaração Relativa aos Direitos e Princípios Fundamentais no Trabalho e seu seguimento adotada em 1998: (i) liberdade sindical e reconhecimento efetivo do direito de negociação coletiva; (ii) eliminação de todas as formas de trabalho forçado; (iii) abolição efetiva do trabalho infantil; (iv) eliminação de todas as formas de discriminação em matéria de emprego e ocupação), a promoção do emprego produtivo e de qualidade, a extensão da proteção social e o fortalecimento do diálogo social. ${ }^{11}$

Quando o país assume o compromisso de integrar a OIT, obriga-se a cumprir as normas básicas da organização. Como tal, os Estados membros devem seguir o estabelecido na Declaração Relativa aos Direitos e Princípios Fundamentais no Trabalho e seu seguimento adotado em 1998. Este documento foi elaborado na $86^{\text {a }}$ Sessão da Conferência Internacional do Trabalho, em Genebra.

Várias preocupações do mundo atual não foram esquecidas por esta Declaração, citando-se de forma exemplificativa o progresso social, a erradicação da pobreza, pessoas com necessidades sociais especiais (com enfoque nos desempregados e trabalhadores migrantes) e o seguinte objetivo de grande relevo:

[...] manter o vínculo entre progresso social e crescimento econômico, a garantia dos princípios e direitos fundamentais no trabalho reveste-se de especial significado ao assegurar aos próprios interessados a possibilidade de reivindicar livremente e em igualdade de oportunidades uma participação justa na riqueza para a qual têm contribuído para gerar, assim como a de desenvolver plenamente seu potencial humano. ${ }^{12}$

A citada Declaração se propôs a identificar as áreas nas quais seria necessária a assistência da OIT, por meio de atividades de cooperação técnica,

11 ORGANIZAÇÃO INTERNACIONAL DO TRABALHO. Promovendo o trabalho decente. Disponível em: <http://www.oit.org.br/content/o-que-e-trabalho-decente> Acesso em: 02 set. 2011.

12 Declaração da OIT sobre os princípios e direitos fundamentais no trabalho e seu segmento. Disponível em: <http://www.oit.org.br/sites/default/files/topic/international_labour_standards/ pub/declaracao_direitos_fundamentais_294.pdf>. Acesso em: 02 set. 2011. 
auxiliando seus Estados membros a tornar efetivos os princípios e direitos fundamentais, sendo este um dos objetivos gerais, como consultado ${ }^{13}$. Ficou proposto que a cada ano fosse feito um procedimento simplificado (substituindo o anterior quadrienal) em relação aos países que ainda não tivessem ratificado as Convenções consideradas fundamentais. Ficou convencionada a confecção de um relatório global, a ser submetido à Conferência Internacional do Trabalho. A elaboração é de responsabilidade do diretor geral, que o confeccionará tendo como base informações oficiais ou as reunidas e avaliadas de acordo com os procedimentos estabelecidos.

Pela Declaração, haverá de certa forma uma avaliação global dos Estados membros para a verificação do cumprimento ou não dos direitos fundamentais: liberdade sindical e o reconhecimento efetivo do direito de negociação coletiva, eliminação de todas as formas de trabalho forçado ou obrigatório, efetiva abolição do trabalho infantil e eliminação da discriminação em matéria de emprego e ocupação.

\section{A incorporação da Agenda do Trabalho Decente nos países do Mercosul}

O relatório Trabalho Decente nas Américas: uma Agenda Hemisférica, 2006-2015, apresenta uma agenda hemisférica de políticas gerais e específicas, cuja execução permitirá avançar na promoção do trabalho decente para todos. Ressalta o referido relatório que cada país deverá determinar qual combinação das políticas sugeridas se adapta melhor às características, particularidades e potencialidades nacionais.

Assim, a agenda hemisférica proposta compõe-se de três elementos fundamentais: a) políticas gerais em quatro âmbitos (normas do trabalho, oportunidades de emprego e renda, proteção social, tripartismo e diálogo social), cuja execução, adequando-as às particularidades e especificidades nacionais, permitiria avançar significativamente na consecução dos objetivos estratégicos e transversais que orientam a estratégia da OIT para a geração de trabalho decente; b) políticas em áreas de intervenção específicas, que contribuam para reforçar as políticas propostas nas quatro áreas gerais; e c) mecanismos para a execução dessas políticas.

No tocante aos aspectos dos programas institucionais de trabalho decente por país, seu objetivo segundo a Agenda Hemisférica é desenvolver as capacidades requeridas para a implantação das políticas consideradas nos programas de trabalho por país, sendo que suas metas são:

\footnotetext{
13 Declaração da OIT sobre os princípios e direitos fundamentais no trabalho e seu segmento. Disponível em: <http://www.oit.org.br/sites/default/files/topic/international_labour_standards/ pub/declaracao_direitos_fundamentais_294.pdf> Acesso em: 02 set. 2011.
} 
1- Nos próximos 10 anos, é preciso melhorar a capacidade de gestão das políticas públicas.

2- Fortalecer e desenvolver as organizações dos atores sociais, assim como os processos e instâncias de diálogo social.

3- Fortalecer a autoridade do trabalho para que ela passe a contar com um potencial de detecção de infrações $50 \%$ superior em relação à sua capacidade atual.

4- Desenvolver a base de conhecimentos sobre o funcionamento do mercado de trabalho e sobre as condições de trabalho, com sistemas integrados e modernos de estatísticas do trabalho.

Os Estados partes do Mercosul, em 2008 , assinaram o termo de compromisso para promoção do trabalho decente que considerando a importância de compartilhar diretrizes relacionadas à melhoria das condições de trabalho no âmbito dos Estados partes e do marco da integração do Mercosul, resolvem:

Art. $1^{\circ}$ - Reafirmar, por meio da assinatura do presente Termo de Compromisso, sua vontade política de promover desenvolvimento com justiça social e inclusão pelo trabalho decente, comprometendo-se a:

I - desenvolver ações relacionadas à promoção de trabalho decente, entendido como uma ocupação produtiva, adequadamente remunerada, exercida em condições de liberdade, equidade e segurança, capaz de proporcionar uma vida digna;

II - estabelecer instrumentos de coordenação e articulação das políticas econômicas, sociais, produtivas e de trabalho por meio do desenvolvimento de Agendas locais de Trabalho Decente;

III - cooperar com outros membros subnacionais que desejem desenvolver atividades semelhantes, especialmente no âmbito do Foro Consultivo de municípios, estados federados, províncias e departamentos do Mercosul.

Art. $2^{\circ}[\ldots]$ os signatários desenvolverão Agendas locais de Trabalho Decente em conformidade com a Agenda Hemisférica de Trabalho decente e as Agendas ou Programas Nacionais de Trabalho Decente, além da consonância com a estratégia Mercosul de crescimento do Emprego (Mercosul/CMC/Dec. No4/6).

\section{O trabalho decente no Brasil}

O compromisso assumido entre o ex-presidente Lula e o diretor geral da OIT em junho de 2003 no que se refere ao trabalho decente teve como prioridade:

1- Gerar mais e melhores empregos, com igualdade de oportunidade e de tratamento. 
2- Erradicar o trabalho escravo e o trabalho infantil, em especial nas suas piores formas.

3- Fortalecer os atores tripartites e o diálogo social como um instrumento de governabilidade democrática.

A partir dessas prioridades, a Agenda do Trabalho Decente no Brasil vem sendo constituída a partir do desenvolvimento de agendas sub-nacionais de trabalho decente. Tal experiência segue a metodologia utilizada pelas demais políticas públicas que são as organizações de conferências realizadas nos âmbitos municipais, estadual e nacional. As conferências configuram-se como espaços de negociação e deliberação com representação de governantes e da sociedade civil organizada. Até o momento, o Brasil já possui a Agenda Bahia do trabalho decente (2007), Agenda Mato Grosso pelo trabalho decente (2009), Agenda Regional do trabalho decente da grande região (composta por 7 municípios) do ABC paulista (2010) e Agenda do trabalho decente de Curitiba (2011).

As propostas estaduais servirão de base de discussão para a Conferência Nacional do Trabalho decente, a ser realizada em 2012, a qual terá como lema: Gerar emprego e trabalho decente para combater a pobreza e as desigualdades sociais, guardando estreita sintonia e articulação com uma das questões centrais enfatizadas pela presidente Dilma Rousseff, a luta pela erradicação da pobreza extrema no Brasil.

Outro aspecto a ser ressaltado no Brasil foi o lançamento, em maio de 2010, do Plano Nacional de Emprego e Trabalho Decente, o qual tem como desafio: garantir que o emprego seja tratado como elemento central das Políticas Públicas. Representa igualmente uma contribuição ao Pacto Mundial pelo Emprego, à Agenda Hemisférica do Trabalho Decente, às Metas e Objetivos do Milênio e a cooperação sul, fortalecendo as estratégias globais de combate à pobreza.

\section{Considerações finais}

Percebe-se que o Brasil avançou nos compromissos assumidos no que se refere à organização de uma agenda do trabalho decente, mas segundo o Plano Nacional do Trabalho decente são problemas a serem enfrentados: a pobreza e a desigualdade social; o desemprego e a informalidade; a extensão da cobertura da proteção social; a parcela de trabalhadoras e trabalhadores sujeitos a baixos níveis de rendimentos e produtividade; os elevados índices de rotatividade no emprego; as desigualdades de gênero e raça/etnia; as condições de segurança e saúde nos locais de trabalho, sobretudo na zona rural.

Já o Perfil do Trabalho Decente no Brasil (2009) apresenta como desafios: erradicação do trabalho infantil, o desemprego juvenil e um grande 
número de jovens que não trabalham e não estudam. Além destas questões, não se pode deixar de evidenciar a necessidade de harmonização trabalhista no âmbito do Mercosul.

\section{Referências}

BARROS, Cassio Mesquita. Perspectivas do direito do trabalho no Mercosul. São Paulo: LTr, 2011.

BEAUDONNET, Xavier. Direito internacional do trabalho e direito interno. Turim: Centro Internacional de Formação da OIT, 2011.

HUSEK, Carlos Roberto. Curso de direito internacional público. 2. ed. São Paulo: LTr, 1998.

MAGALHÃES, Maria Lúcia Cardoso de. A harmonização dos direitos sociais e o Mercosul. Revista do Tribunal Regional do Trabalho da $3^{\mathbf{a}}$ Região. Belo Horizonte, v.32, n.62, p.51-65, jul/dez 2000.

SÜSSEKIND, Arnaldo. Direito internacional do trabalho. 3. ed. São Paulo: LTr, 2000.

VIGEVANI, Tullo. Mercosul: impactos para trabalhadores e sindicatos. São Paulo: LTr, 1998.

Sites consultados:

COMISSÃO SÓCIO-LABORAL E SGT-10. Disponível em: <http://www.mte.gov. br/rel_internacionais/comissao_sociolaboral.asp>. Acesso em: 02 setembro 2011.

CONSTITUIÇÃO DA ORGANIZAÇÃO INTERNACIONAL DO TRABALHO (OIT) E SEUS ANEXOS. Disponível em: < http://www.oit.org.br/ sites/default/files/topic/decent_work/doc/constituicao_oit_538.pdf>. Acesso em: 02 setembro 2011.

COORDINADORA DE CENTRALES SINDICALES DEL CONO SUR. Disponível em: http://www.ccscs.org/. Acesso em: 04 setembro 2011.

\section{DECLARAÇÃO DA OIT SOBRE OS PRINCÍPIOS E DIREITOS} FUNDAMENTAIS NO TRABALHO E SEU SEGUIMENTO. Disponível em: $<$ http://www.oit.org.br/sites/default/files/topic/international_labour_standards/ pub/declaracao_direitos_fundamentais_294.pdf> Acesso em: 02 setembro 2011.

DECLARAÇÃO ESPECIAL DOS PRESIDENTES DOS ESTADOS PARTES DO MERCOSUL E ESTADOS ASSOCIADOS SOBRE MIGRAÇÕES.

Disponível em: <http://www.mercosul.gov.br/comunicados/2010/declaracaoespecial-dos-presidentes-dos-estados-partes-do-mercosul-e-estados-associadossobre-migracoes $>$. Acesso em: 05 setembro 2011. 
DECLARAÇÃO SOCIOLABORAL DO MERCOSUL. Disponível em: <http://www.stf.jus.br/arquivo/cms/forumCorteSupremaNorma/forumCorte SupremaNorma_AP_75320.pdf>. Acesso em: 02 set. 2011.

FÓRUM INTERNACIONAL SOBRE DIREITOS SOCIAIS. Disponível em: <http://www.tst.gov.br/ASCS/forum/comissao.html>. Acesso em: 02 set. 2011.

MERCOSUR/GMC/CSL/Acta 1/06 - XIX REUNIÓN DE LA COMISIÓN SOCIOLABORAL DEL MERCOSUR. Disponível em: <http://www3.mte.gov. br/rel_internacionais/ActaCSLFINAL23_06_2006.pdf>. Acesso em: 24 junho 2012.

MERCOSUL SOCIAL E PARTICIPATIVO. Disponível em: < http://www. mercosul.gov.br/mercosul-social-e-participativo>. Acesso em 05 setembro 2011.

OBSERVATÓRIO. Disponível em: <http://www.observatoriomercosur.org.uy/ pr/observatorio.php>. Acesso em: 24 junho 2012.

ORGANIZAÇÃO INTERNACIONAL DO TRABALHO. Promovendo O trabalho decente. Disponível em: < http://www.oit.org.br/content/o-que-e-trabalhodecente $>$. Acesso em 02 setembro 2011.

ORGANIZAÇÃO INTERNACIONAL DO TRABALHO. Promovendo o trabalho decente. Disponível em: < http://www.oit.org.br/content/o-que-e-trabalhodecente $>$. Acesso em 02 setembro 2011.

TRABALHO DECENTE NAS AMÉRICAS: uma agenda hemisférica, 20062015. Disponível em: < http://pt.redcontraeltrabajoinfantil.fundacaotelefonica.com/ ckeditor_assets/attachments $/ 110 /$ pt. $\% 20$ Agenda $\% 20$ hemisf $\%$ C $3 \%$ A 9 rica $\% 20$ de $\% 20$ trabalho $\% 20$ decente $\% 202006-2015 \% 20(101)$.pdf $>$. 